\title{
Islanded Mode Response Verification of AC Microgrid under Symmetrical and Non-symmetrical Short Circuits
}

\author{
Maruf A. Aminu* \\ Department of Electrical and Electronics Engineering, Faculty of Engineering, Nile University of Nigeria, Abuja, Nigeria
}

\begin{abstract}
The assumptions and parameters required in modeling a microgrid depend on the platform, among other variables. It is therefore pertinent to verify the response of a modeled testbed to establish its validity. This work reports on verification of the response of a wind turbines-based microgrid to symmetrical and non-symmetrical short circuits. The testbed consists of 2 units of $5.5 \mathrm{~kW} 400 \mathrm{~V}$ wind turbines capable of connecting to the utility. Short circuits are introduced at 6.00 second and withdrawn at 8.00 second, measuring the dynamic response of the testbed while the microgrid is in islanded mode alternately under voltage and reactive power control strategies. The response is shown to be consistent, symptomatic of the type of short circuit and therefore suitable for short circuit detection and diagnosis, verifying validity of the microgrid testbed. The testbed can therefore be used for short circuit related studies, design optimization and performance prediction.
\end{abstract}

\section{Introduction}

A power system operator is primarily concerned with production and processing of sufficient energy to meet declared demand, resulting in need for optimal operation of the system. Optimal operation of power system is dependent on frequency of shutdown occasioned by open circuit and short circuit faults. All short circuit faults, symmetrical or non-symmetrical, result in low impedance and high current which lead to insulation failure and consequent damage of the system if the short circuit is not interrupted sufficiently quickly. Protective devices are employed to interrupt short circuits by isolating, if possible, only affected sections of the system [1]-[4]. Every short circuit protective device includes a detection network or circuit. The detection network measures critical variables and detects onset of short circuit by comparing the variable with reference or preset variable(s) [5]. Protective devices function to ensure:

1. minimal damage and repair costs in an event of fault.

2. safeguard of the system to ensure supply continuity.

3. safety of personnel [6]-[10].

A statutory requirement of a protective device is reliability, low cost, high response speed, capability to select between faulted and normal segments of the system, and be sufficiently sensitive to faults [11].

Using dynamic analysis, this work presents verification of the responses of a microgrid testbed to short circuits of the type: line-to-ground, line-to-line, double line-to-ground, bolted three phase and crosscountry. Dynamic analysis depicts the sub-transient, transient and steady-state variation of critical parameters of the system [12]. In addition to protective systems, power systems require control devices for optimal operation [13]. Design of engineering systems require performance prediction and optimization using system models [14]-[17].

The testbed is modeled to operate under two control strategies; voltage $(V)$ and reactive power $(Q)$ controls. The controller maintains $4 \%$ droop under $V$ control while it maintains constant reactive power at the grid under $Q$ control even when the system is stressed with short circuit(s). The microgrid consists of two wind turbines (WTs) servicing two local loads.

\section{System modeling}

The system is modeled in SimPowerSystems using a 100 MW $13.8 \mathrm{kV}$ utility and connected to the microgrid through a point of common coupling (PCC). The microgrid consists of two microsources, each rated 5.5 $\mathrm{kW} 400 \mathrm{~V}$. The distribution feeders are modeled using lumped parameter method. Figure 1 provides a block representation of the modeled system. The three-phase stator voltage of each WT is transformed to stationary dc reference frame using Edith Clarke's transformer presented in equation (1).

$$
v_{\alpha \beta \gamma}(t)=\frac{2}{3}\left[\begin{array}{ccc}
1 & -\frac{1}{2} & -\frac{1}{2} \\
0 & \frac{\sqrt{3}}{2} & -\frac{\sqrt{3}}{2} \\
\frac{1}{2} & \frac{1}{2} & \frac{1}{2}
\end{array}\right]\left[\begin{array}{l}
v_{a}(t) \\
v_{b}(t) \\
v_{c}(t)
\end{array}\right]
$$

Corresponding author: maruf.aminu@gmail.com 
where,

$v_{\alpha \beta \gamma}(t)$ is a vector representing the $\alpha, \beta$ and $\gamma$ components of the transformed voltage. $v_{a}(t), v_{b}(t)$ and $v_{c}(t)$ represent components of voltage in $a b c$ reference frame.

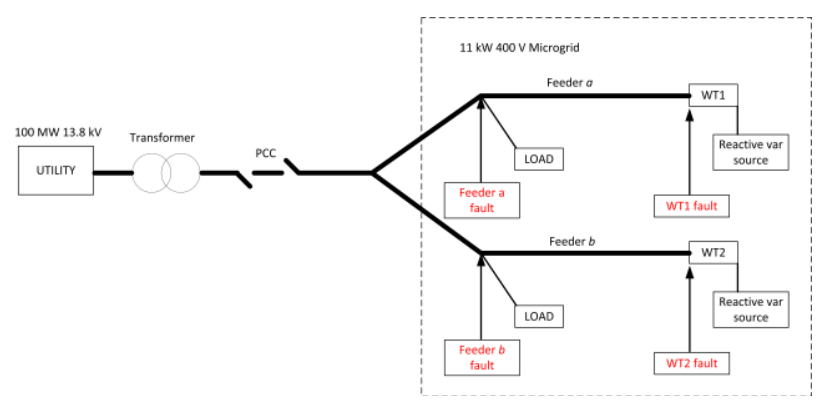

Fig. 1. Block diagram showing the major elements of the modeled system

\section{Simulation of short circuits and system responses}

Four types of short circuits are applied at different positions of the microgrid when the PCC is open, i.e. when the microgrid is islanded. The short circuits are bolted three phase, single line-to-ground, double line-toline and three phase cross-country. The three-phase crosscountry involves applying three phase short circuit across terminals of both wind turbine 1 (WT1) and wind turbine 2 (WT2). The dynamic response plots of the three-phase WT stator voltage in stationary dc reference frame under short circuits in both control strategies are presented. The short circuit is applied at 6.00 second and withdrawn at 8.00 second.

Figure 2 presents the nominal response of WT1 during normal operation under both control strategies. In each of Figure 3 to Figure 10, the three-phase active power $[\mathrm{P}(\mathrm{W})]$ in Watts and three-phase reactive power $[\mathrm{Q}($ var $)]$ in var are presented.
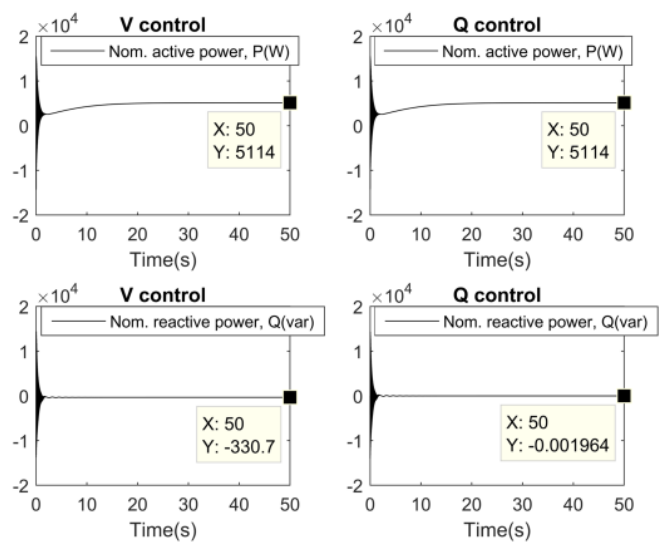

Fig. 2. Normal response of WT1 under $V$ and $Q$ controls

Figures 3 and 4 present the responses of WT1 when its terminals are short-circuited at 6.00 second while the 3 -phase short circuit is withdrawn at 8.00 second under $V$ and $Q$ controls respectively.
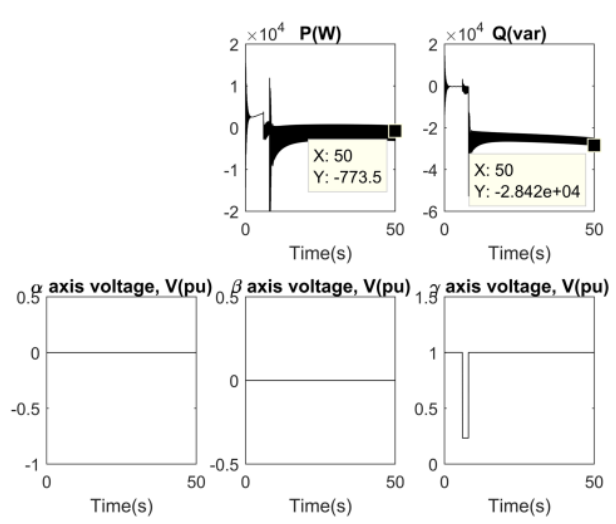

Fig. 3. Response of WT1 to 3-phase short circuit under $V$ control
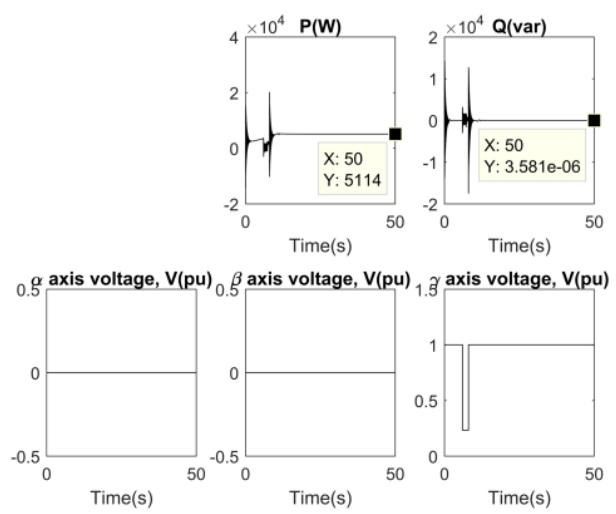

Fig. 4. Response of WT1 to 3-phase short circuit under $Q$ control

In Figures 5 and 6, the responses of WT2 when 3phase short circuit is applied to the terminals of MS1 under $V$ and $Q$ controls are depicted respectively. Figure 5 shows that response of MS1 is instant, indicating high speed of short circuit detection. Figure 6 shows nonresponse of WT2 to short circuit at WT1, indicating selectivity and sensitivity in the response of the testbed.
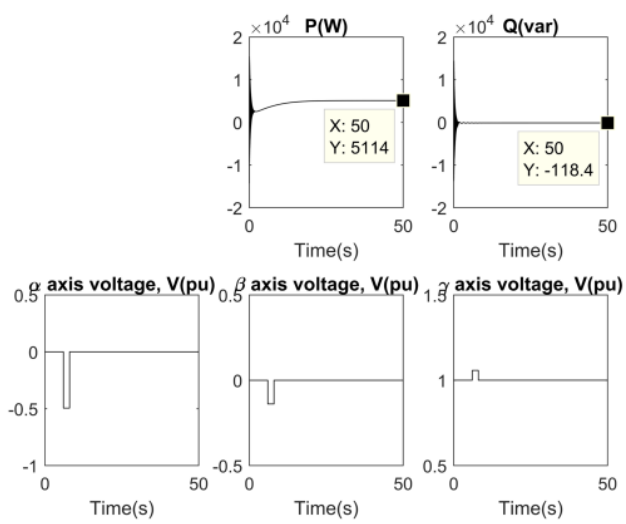

Fig. 5. Response of WT2 to line-to-ground short circuit at WT1 under $V$ control 

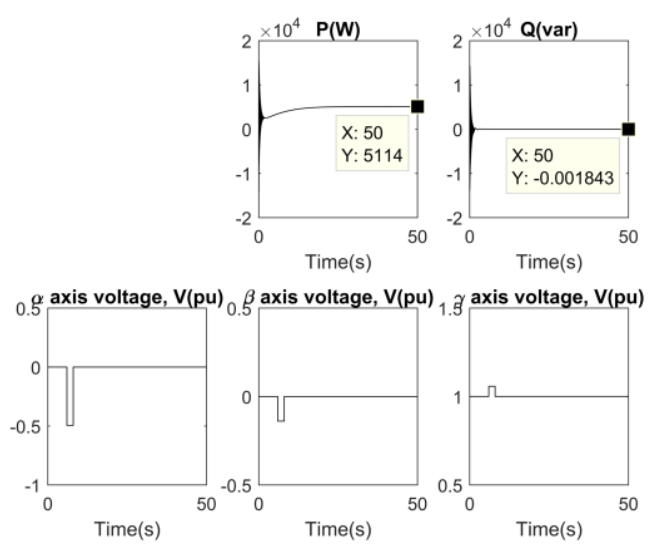

Fig. 6. Response of WT2 to line-to-ground short circuit at WT1 under $Q$ control

In addition to application of 3-phase bolted short circuit at each WT, the end of feeder $a$ (at PCC) is shortcircuited while measuring the response of WT1. During this short circuit condition, the responses of WT1 under $V$ and $Q$ controls are depicted in Figures 7 and 8 respectively.
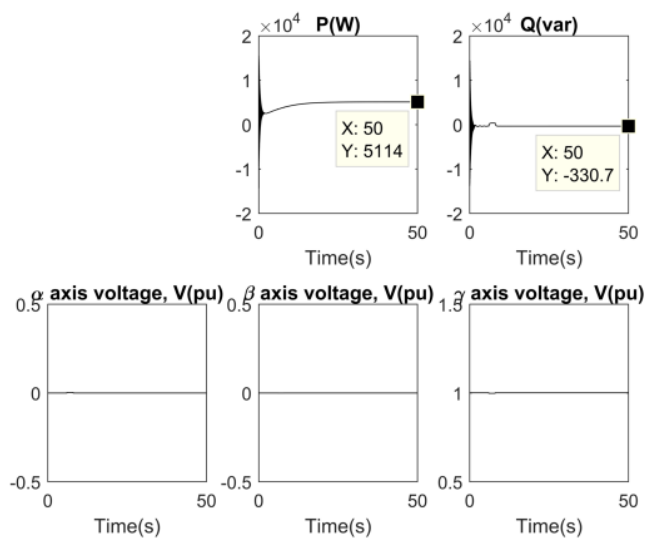

Fig. 7. Response of WT1 to line-to-line short circuit at feeder $a$ under $V$ control
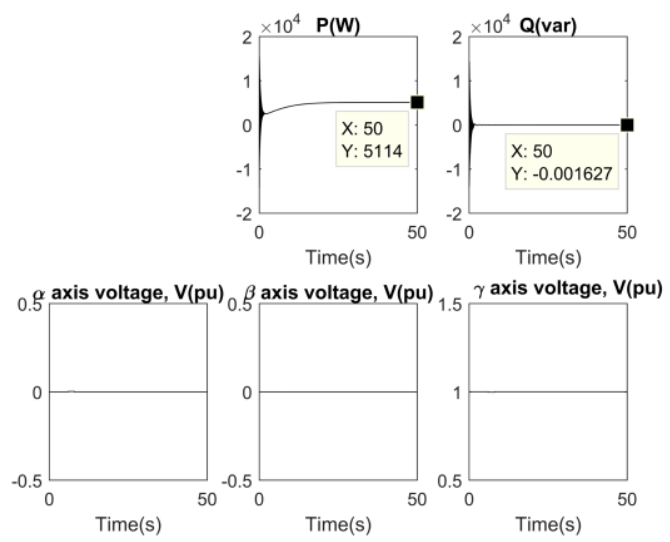

Fig. 8. Response of WT1 to line-to-line short circuit at feeder $a$ under $Q$ control

Figures 9 and 10 present responses of WT1 to crosscountry (WT1 and WT2) 3-phase short circuit under $V$ and $Q$ controls respectively.
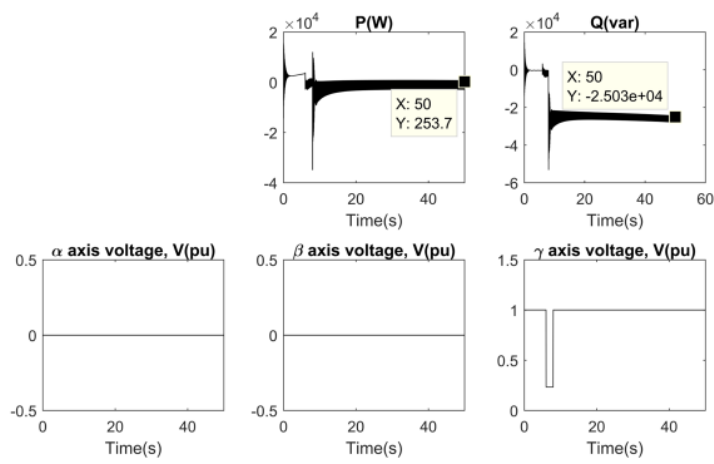

Fig. 9. Response of WT1 to 3-phase cross-country short circuit under $V$ control
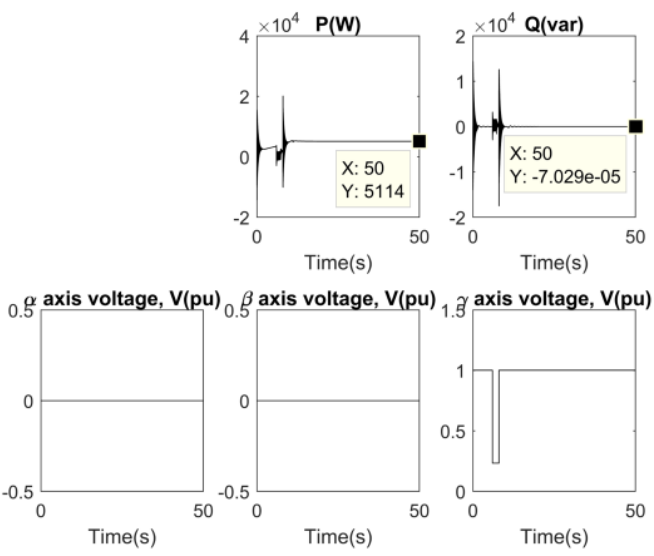

Fig. 10. Response of WT1 to 3-phase cross-country short circuit under $Q$ control

\section{Discussion of results}

When the testbed is free of short circuit, either of the wind turbines generates $5.114 \mathrm{~kW}$, representing $92 \%$ of its nominal active power (Figure 2). This is regardless of control strategy. Note that reactive power demand is more in $V$ control than in $Q$ control, indicating that the internal capacitor bank supports its reactive demand. This is indicative of superior reactive power management under $Q$ control than under $V$ control. In Figures 3 and 4, the 3-phase short circuit triggers voltage oscillation which is more disruptive under $V$ control. At $50.00 \mathrm{~s}$ after the short circuit is withdrawn, WT1 is unable to achieve steady-state due to virulence of the disturbance under $V$ control. In Figures 7 and 8, WT1 responds to the short circuit at feeder $a$ with superior performance under $Q$ control. Consistent trend of response of WT1 to the short circuits is observed in Figures 5 to 10. In Figures 2 to 10, the pattern of the per-unit $\alpha-, \beta-$ and $\gamma-$ voltage is consistent with the location and type of short circuit. This is symptomatic of the short circuit and therefore suitable for short circuit detection, classification and diagnosis. The figures have also shown that the response of the testbed to short circuit satisfies requirements of high speed, selectivity and sensitivity. Dynamic response of 
the testbed to the short circuits is therefore verified to be valid and consistent with established short circuit theory [18]-[21].

\section{Conclusion}

This work simulates symmetrical and non-symmetrical short circuits in an islanded microgrid. The dynamic response of the testbed is measured pre--, during- and post-short circuit under voltage and reactive power control strategies. The response is shown to be consistent, symptomatic of the type of short circuit and therefore suitable for short circuit detection, classification and diagnosis. The dynamic response of the testbed to the short circuits is therefore verified to be valid and consistent with established short circuit theory.

\section{References}

1. G. Didier, C. H. Bonnard, T. Lubin, and J. Lévêque, "Comparison between inductive and resistive SFCL in terms of current limitation and power system transient stability," Electric Power Systems Research, vol. 125, pp. 150-158, 2015.

2. S. V. Papaefthymiou, V. G. Lakiotis, I. D. Margaris, and S. A. Papathanassiou, "Dynamic analysis of island systems with wind-pumped-storage hybrid power stations," Renewable Energy, vol. 74, pp. 544554, 2015.

3. B. Rona and Ö. Güler, "Power system integration of wind farms and analysis of grid code requirements," Renewable and Sustainable Energy Reviews, vol. 49, pp. 100-107, 2015.

4. F. Sulla, J. Svensson, and O. Samuelsson, "Symmetrical and unsymmetrical short-circuit current of squirrel-cage and doubly-fed induction generators," Electric Power Systems Research, vol. 81, no. 7, pp. 1610-1618, 2011.

5. M. A. Aminu, "Modeling and Simulation of Protective Relay for Short Circuits in AC Micro-grids using Fuzzy Logic," Curtin University, Perth, Australia, 2016.

6. M. Chaudhary, S. M. Brahma, and S. J. Ranade, "Validated short circuit modeling of Type 3 Wind Turbine Generator with crowbar protection," presented at the North American Power Symposium (NAPS), 2013, 2013, pp. 1-6.

7. O. E. Roennspiess and A. E. Efthymiadis, "A comparison of static and dynamic short circuit analysis procedures," IEEE Transactions on Industry Applications, vol. 26, no. 3, pp. 463-475, 1990.

8. N. Soni, S. Doolla, and M. C. Chandorkar, "Improvement of Transient Response in Microgrids Using Virtual Inertia," IEEE Transactions on Power Delivery, vol. 28, no. 3, pp. 1830-1838, 2013.

9. O. Palizban, K. Kauhaniemi, and J. M. Guerrero, "Microgrids in active network management - part II: System operation, power quality and protection," Renewable and Sustainable Energy Reviews, vol. 36, pp. 440-451, 2014.
10. I. Patrao, E. Figueres, G. Garcerá, and R. GonzálezMedina, "Microgrid architectures for low voltage distributed generation," Renewable and Sustainable Energy Reviews, vol. 43, pp. 415-424, 2015.

11. J. Schomaker, "Overcurrent protective devices preserve system integrity," Plant Engineering, vol. 59, no. 6, pp. 48-54, Nov. 2005.

12. M. A. Aminu, "Validating response of AC Micro-grid to Three Phase Short Circuit in Grid-connected Mode using Dynamic Analysis," International Journal of Electrical Components and Energy Conversion, vol. 2, no. 4, pp. 21-34, 2016.

13. M. A. Aminu, "Design of Reactive Power and Voltage Controllers for Converter-interfaced ac Microgrids," British Journal of Applied Science \& Technology, vol. 17, no. 1, 2016.

14. P. Tchakoua, R. Wamkeue, M. Ouhrouche, T. A. Tameghe, and G. Ekemb, "A New Approach for Modeling Darrieus-Type Vertical Axis Wind Turbine Rotors Using Electrical Equivalent Circuit Analogy: Basis of Theoretical Formulations and Model Development.," Energies (19961073), vol. 8, no. 10, pp. 10684-10717, Oct. 2015.

15. K. P'yankov and M. Toporkov, "Mathematical modeling of flows in wind turbines with a vertical axis.," Fluid Dynamics, vol. 49, no. 2, pp. 249-258, Mar. 2014.

16. Y. Bazilevs, A. Korobenko, X. Deng, and J. . Yan, "Novel structural modeling and mesh moving techniques for advanced fluid-structure interaction simulation of wind turbines.," International Journal for Numerical Methods in Engineering, vol. 102, no. 3/4, pp. 766-783, Apr. 2015.

17. F. Xu, F.-G. Yuan, L. Liu, J. Hu, and Y. Qiu, "Performance Prediction and Demonstration of a Miniature Horizontal Axis Wind Turbine.," Journal of Energy Engineering, vol. 139, no. 3, pp. 143-152, Aug. 2013.

18. J. Li, T. Zheng, and Z. Wang, "Short-Circuit Current Calculation and Harmonic Characteristic Analysis for a Doubly-Fed Induction Generator Wind Turbine under Converter Control.," Energies (19961073), vol. 11, no. 9, p. 2471, Sep. 2018.

19. T. Sellami, H. Berriri, S. Jelassi, A. M. Darcherif, and M. F. Mimouni, "Short-Circuit Fault Tolerant Control of a Wind Turbine Driven Induction Generator Based on Sliding Mode Observers.," Energies (19961073), vol. 10, no. 10, p. 1611, Oct. 2017.

20. M. Eftekhari a. mohsen. eftekhari@gmail. co., A. S. Molavi Tabrizi a. saman. molavi@gmail. co., and S. M. Sadeghzadeh sadeghzadeh@shahed. ac. i., "The Effect of Resistive-type Superconducting Fault Current Limiters on the Test Feeder with Windturbine Generation System.," IETE Journal of Research, vol. 58, no. 5, pp. 411-417, Oct. 2012.

21. X. Y. Zheng zheng. xiangyuan@sz. tsinghua. edu. c. and Y. Lei 2, lei-y16@mails.tsinghua.edu.cn, "Stochastic Response Analysis for a Floating Offshore Wind Turbine Integrated with a Steel Fish Farming Cage.," Applied Sciences (2076-3417), vol. 8, no. 8, p. 1229, Aug. 2018. 